\title{
Sex-Dependent Adverse Drug Reactions to 5-Fluorouracil in Colorectal Cancer
}

\author{
Hyesol Lim, ${ }^{a}$ Sun Young Kim, ${ }^{b}$ Eunhye Lee, ${ }^{a}$ Seungeun Lee, ${ }^{a}$ Sungryong Oh, ${ }^{a}$ Joohee Jung, ${ }^{a}$ \\ Kwi Suk Kim, ${ }^{c}$ and Aree Moon*,a \\ ${ }^{a}$ Duksung Innovative Drug Center, College of Pharmacy, Duksung Women's University; 33, Samyang-ro 144 gil, \\ Dobong-gu, Seoul 01369, Korea: ${ }^{b}$ Department of Chemistry, College of Natural Sciences, Duksung Women's \\ University; 33, Samyang-ro 144 gil, Dobong-gu, Seoul 01369, Korea: and ${ }^{c}$ Department of Pharmacy, Seoul National \\ University Hospital; 101 Daehak-ro, Jongno-gu, Seoul 03080, Korea.
}

Received September 12, 2018; accepted December 22, 2018

Sex-related incidence and outcomes were reported in various cancers, including colorectal cancer. 5-Fluorouracil (5-FU) is widely used as an essential chemotherapeutic agent for colorectal cancer. However, sexbased differences in 5-FU toxicity have yet to be reported in human cancer cell lines and xenograft mouse models to date. Here, we investigated, for the first time, sex-based differences in 5-FU toxicity using human colon cancer cell lines, xenograft mouse models, and Korean patients' data. Female-derived colon cancer cell lines exhibited greater 5-FU-induced cytotoxicity than male-derived colon cancer cell lines. We established two xenograft mouse models: one with a male-derived human colon cancer cell line injected into male mice (a male-xenograft model) and another involving a female-derived human colon cancer cell line injected into female mice (a female xenograft model). Treatment with 5-FU inhibited tumor growth and led to hematological toxicity in a female xenograft model more potently than in a male xenograft model. We analyzed the data obtained from Korean patients with colorectal cancer to examine sex differences in adverse drug reactions caused by 5-FU. Korean female patients with colorectal cancer who received 5-FU chemotherapy experienced more frequent adverse drug reactions including alopecia and leukopenia than male patients. Taken together, we demonstrated that female may be associated with increased risk of toxicity to 5-FU treatment in colorectal cancer based on in vitro and in vivo investigations and clinical data analysis. Our study suggests sex as an important clinical factor, which predicts induction of toxicity related to 5-FU treatment.

Key words sex; toxicity; 5-fluorouracil; adverse drug reaction; colorectal cancer

\section{INTRODUCTION}

Growing evidence suggests that there are sex differences in the incidence, aggressiveness, and survival of various cancers. ${ }^{1,2}$ However, the proportion of animal studies and clinical trials involving males was higher than those involving females. ${ }^{3-5)}$ In addition, clinical chemotherapies have been prescribed in similar doses between men and women. $\left.{ }^{6}\right)$ Although most studies on sex-dependent difference have been performed based on human data, a recent paper used cultured cells for investigating the effect of gender on drug-induced cytotoxicity. ${ }^{7)}$ All human cell lines were established from male or female individuals. ${ }^{8,9)}$ It is important to precisely acknowledge sex of cell lines before conducting any research using cell lines because sex chromosomes in cell lines may attribute to biological mechanisms, pathways and pharmacological treatment. $^{8-10)}$

Sex-related incidence and outcomes have been reported in colorectal cancer. ${ }^{11,12)}$ Colorectal cancer is the most frequently diagnosed disease and common cause of cancer-related deaths worldwide, although the survival rate has increased due to early detection. ${ }^{13,14)}$ In Korea, colorectal cancer is the leading cause of death in both men and women since $1983 .{ }^{15)}$ Men manifest a higher incidence of colorectal cancer. ${ }^{16)}$ Diseasefree and overall survival is significantly longer in women diagnosed with colorectal cancer compared with men. ${ }^{17)}$

5-Fluorouracil (5-FU) is used as an essential chemotherapeutic agent for the treatment of colorectal cancer. ${ }^{18)}$ Especial- ly, 5-FU/leucovorin (FL) regimen has been established as an effective regimen for patients with resected stage II colorectal cancer. ${ }^{19)}$ It was reported that women treated with 5-FU-based chemotherapy experienced toxicity including alopecia and leukopenia more frequently than men in Caucasian and African American populations. ${ }^{20,21)}$

Sex-specific differences in drug response among Korean patients treated with 5-FU, however, have yet to be analyzed. Further, sex differences in 5-FU-induced toxicity have yet to be determined in experimental studies using colorectal cancer cell lines. Here, we assessed sex-specific differences in 5-FU toxicity using human colon cancer cell lines, two sex-specific xenograft models and data pertaining to Korean patients diagnosed with colorectal cancer. We demonstrated that differences in 5-FU-induced toxicity may be associated with sex in colorectal cancer based on experimental studies and patient data.

\section{MATERIALS AND METHODS}

Cell Culture and Reagents Male-(DLD-1, SW480, LoVo and HCT116) and female-(HT29, WiDr, and SNUC2A) derived colon cancer cells were cultured with an RPMI 1640 (Corning Life Science, Cambridge, MA, U.S.A.) medium supplemented with $10 \%$ fetal bovine serum (FBS) and $1 \%$ penicillin-streptomycin. Male-derived colon cancer cell Caco2 was cultured with MEM medium supplemented with $20 \%$ FBS, $25 \mathrm{mM} N$-2-hydroxyethylpiperazine- $N$ '-2-ethanesulfonic 
acid (HEPES), and $25 \mathrm{mM} \mathrm{NaHCO}_{3}$. All colon cancer cell lines were kindly provided by Prof. Hye Kyung Na (Sungshin University, Seoul, Korea). 5-FU was purchased from SigmaAldrich (St. Louis, MO, U.S.A.) and dissolved in dimethyl sulfoxide (DMSO) (Sigma-Aldrich).

3-(4,5-Dimethylthiazol-2-yl)-2,5-diphenyl-tetrazolium Bromide (MTT) Assay MTT assay was performed as previously described. ${ }^{22)}$ Cells were seeded in a 96-well plate and incubated for $24 \mathrm{~h}$ at $37^{\circ} \mathrm{C}$. Cells were then treated with various concentrations of 5-FU $(0,1,10,50,100,200,500$, and $1000 \mu \mathrm{M}$ ) for $48 \mathrm{~h}$. Following incubation, $5 \mathrm{mg} / \mathrm{mL}$ MTT (Sigma-Aldrich) was added and further incubated for $3 \mathrm{~h}$, until formazan was dissolved in DMSO. The optical density was measured at $540 \mathrm{~nm}$ using a Synergy 2 Multi-Mode Reader (BioTek Instruments, Inc., Winooski, VT, U.S.A.). Each sample was assayed in triplicate.

In Vivo Xenograft Model Balb/c-nude mice (5-week-old, 5 males and 5 females) were purchased from SLC (Shizuoka, Japan). The mice were handled using a protocol approved by Duksung Women's University in accordance with the Guidelines for the Care and Use of Laboratory Animals (No. 2017-002-004). HCT116 and WiDr cells $\left(5 \times 10^{6}\right.$ cells $\left./ 100 \mu \mathrm{L}\right)$ were subcutaneously injected in the right legs of male and female mice, respectively. When tumor volume was greater than approximately $100 \mathrm{~mm}^{3}$, the mice were randomly divided into two groups: control and 5-FU treated groups (each group, $n=5$ ) followed by intraperitoneal injection of $50 \mathrm{mg} / \mathrm{kg}$ of 5-FU three times a week for three weeks. The length and width of tumor were measured by caliper three times a week. The tumor volume was calculated using the following formula: Tumor volume $\left(\mathrm{mm}^{3}\right)=($ tumor length $) \times(\text { tumor width })^{2} / 2$

Hematological Analysis After the mice $(n=5)$ were anesthetized with Zoletil $(25 \mathrm{mg} / \mathrm{kg})$, blood was drawn from inferior vena cava and stored in ethylenediaminetetraacetic acid (EDTA)-tube. Blood cell counts and hematological parameters were analyzed using ADVIA2120i (Siemens, Germany).

Patients The electronic medical records (EMR) of 357 patients with diagnostic codes of colon or rectal cancer from 1 January 2012 to 31 December 2016 were retrieved from Seoul National University Hospital (SNUH), Seoul, Korea. The patients received FL regimen chemotherapy at the SNUH. Clinical characteristics of patients, including age at diagnosis, sex, total follow-up duration, and body mass index were obtained from EMR. Information relevant to colorectal cancer diagnosis, such as site and stage were reviewed via EMR as well. Laboratory findings included the following parameters: serum creatinine, total bilirubin, platelet count, aspartate aminotransferase (AST), alanine aminotransferase (ALT), Blood urea nitrogen (BUN), absolute neutrophil (NEU) count (ANC), and carcinoembryonic antigen (CEA). The study protocol was approved by the Institutional Review Board of SNUH (Approval number: 1702-140-834).

Tumor Node Metastasis (TNM) Staging and Treatment Assessment All patients were diagnosed with pathologically confirmed colorectal cancer and evaluated during their visit at SNUH according to the 2017 version of National Comprehensive Cancer Network (NCCN) guideline. Based on the NCCN guideline, locally advanced tumors or advanced tumors were treated surgically followed by adjuvant chemotherapy with or without radiotherapy.
Measurement of Adverse Drug Reactions on EMR Each adverse drug reaction was defined by several categories. All adverse drug reactions were assessed via EMR and prescribed drug. Neutropenia was based on absolute NEU count (ANC) ( $\leq$ ANC 2000). Alopecia was identified via EMR. Nausea and vomiting were identified using anti-emetics and EMR as well. Diarrhea was identified based on response to $2 \mathrm{mg}$ Loperamide and EMR as well. Hand-foot syndrome was diagnosed by prescribing the $10 \mathrm{~g}$ esperson-vaseline (EV) cream and EMR as well.

Measurement of Adverse Drug Reactions on Spontaneously Reported Data For this study, 1446 cases of adverse drug reaction were extracted from spontaneous adverse drug events reporting system of the Korea Institute of Drug Safety and Risk Management (KIDS) involving adult colorectal cancer patients ( $\geq 19$ years) treated with 5 -FU from 1 January 2011 to 31 December 2015. Terms and classification systems followed the preferred terms (PT) of WHO-adverse reaction terminology (ART) code formulated by the Ministry of Food and Drug Safety (MFDS). We excluded cases of combined medication duplicated reporting, and cases undergoing causality assessment as 'unlikely,' 'unclassified,' and 'unclassifi-

\section{A}

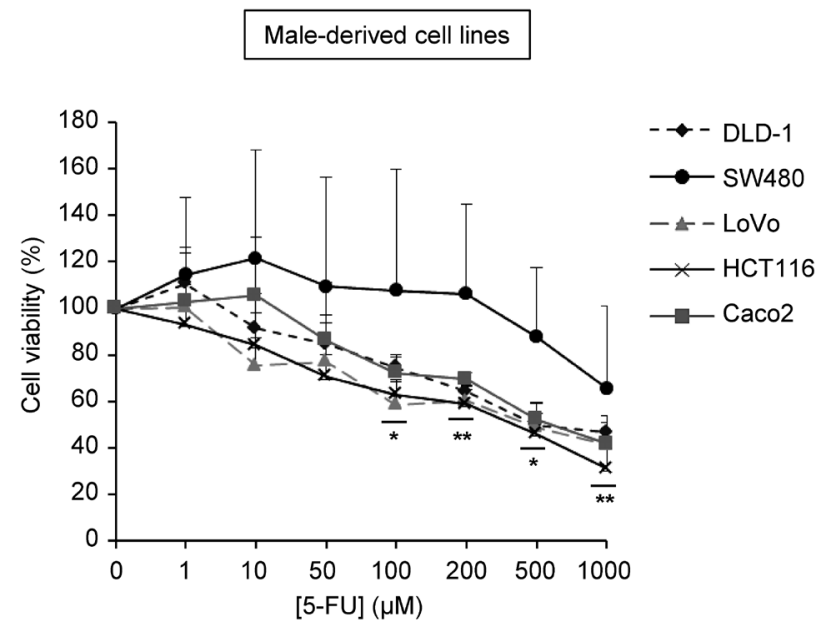

B

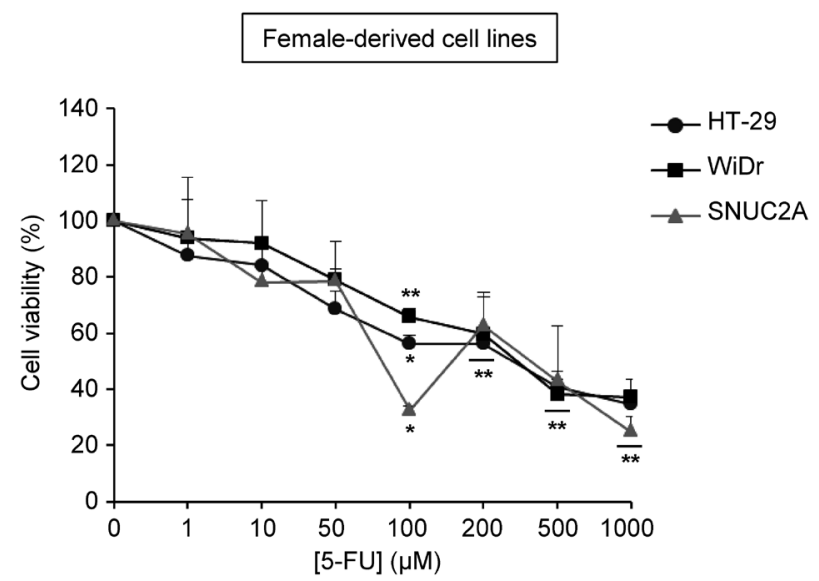

Fig. 1. 5-FU Exerts Higher Cytotoxicity in Female-Derived than in Male-Derived Colon Cancer Cell Lines

(A)-(B), MTT assay was performed in male-(DLD-1, SW480, LoVo, HCF116, and $\mathrm{Caco} 2$ ) (A) and female-(HT-29, WiDr, and SNUC2A) derived colon cancer cell lines (B) treated with 5 -FU for $48 \mathrm{~h}$. Data are expressed as mean \pm S.E. ***Statistically significant at $p<0.05$ and $p<0.01$, respectively. 
able.' We assessed cases for causality assessment as 'certain,' 'probable,' 'possible' according to WHO Uppsala Monitoring Center (UMC) criteria classify.

Statistical Analysis Comparison of baseline characteristics, dosage, adverse drug reactions, and abnormalities according to sex were analyzed using the chi-squared test or independent Student's $t$-test. Statistical analyses were performed

Table 1. $\mathrm{IC}_{50}$ Values of Male- and Female-Derived Colon Cancer Cell Lines Treated with 5-FU

\begin{tabular}{cc}
\hline \hline Cell line & $\mathrm{IC}_{50}(\mu \mathrm{M})$ \\
\hline Male & \\
DLD-1 & 473.8 \\
SW480 & 765.7 \\
LoVo & 772.9 \\
HCT116 & 557.4 \\
Caco2 & 398.4 \\
Female & \\
HT29 & 361.4 \\
WiDr & 358.0 \\
SNUC2A & 393.8
\end{tabular}

$\mathrm{IC}_{50}$ values were determined by MTT assay in each colon cancer cell line treated with 5 -FU for $48 \mathrm{~h}$. using SPSS version 23 (IBM SPSS statistics for windows, IBM Corp., Chicago, IL, U.S.A.). Statistical significance was considered when the $p$-value was less than 0.05 .

\section{RESULTS}

5-FU Exerts Higher Cytotoxicity in Female-Derived Colon Cancer Cell Lines than in Male-Derived Cell Lines To investigate sex differences in 5-FU-induced cytotoxicity in vitro, we performed an MTT assay in male-derived (DLD-1, SW480, LoVo, HCT116, and Caco2) and female-(HT-29, WiDr, and SNUC2A) derived colon cancer cell lines. As shown in Figs. $1 \mathrm{~A}$ and $\mathrm{B}$, treatment with $5-\mathrm{FU}$ for $48 \mathrm{~h}$ was inhibited the growth of male- and female-derived colon cancer cell lines in a dose-dependent manner. Cell viabilities of male-derived colon cancer cell lines DLD-1, SW480, LoVo, HCT116, and Caco2 treated with $1000 \mu \mathrm{M} 5$-FU for $48 \mathrm{~h}$ were 46.7, 65.7, $41.3,31.2$, and $41.9 \%$ of control, respectively (Fig. 1A). Cell viabilities of female-derived colon cancer cell lines HT-29, WiDr, and SNUC2A treated with $1000 \mu \mathrm{M} 5$-FU were 34.8, 37.3 , and $24.8 \%$ of control, respectively (Fig. $1 \mathrm{~B}$ ). The $\mathrm{IC}_{50}$ values of male-derived colon cancer cell lines were higher than those of female-derived colon cancer cell lines treated with 5-FU (Table 1). These results demonstrate that 5-FU

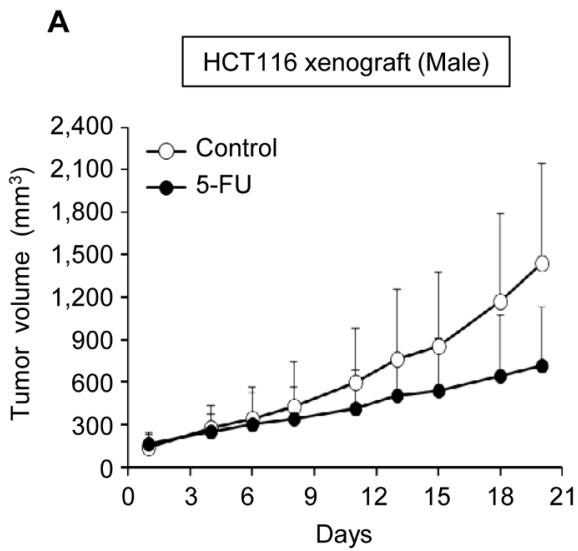

C

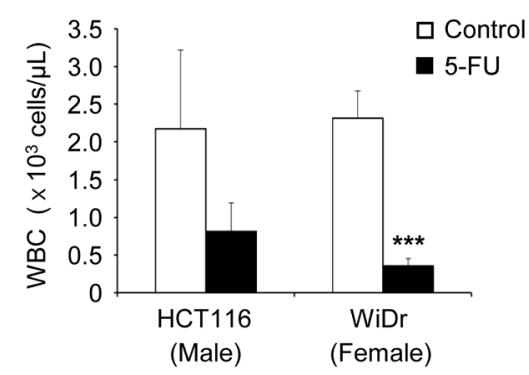

B

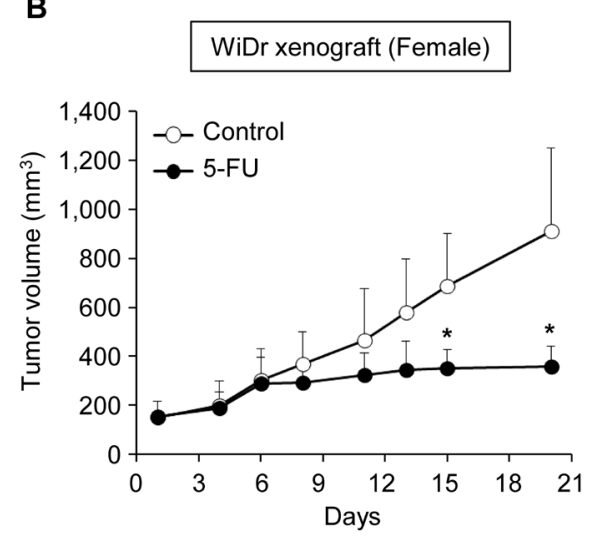

D

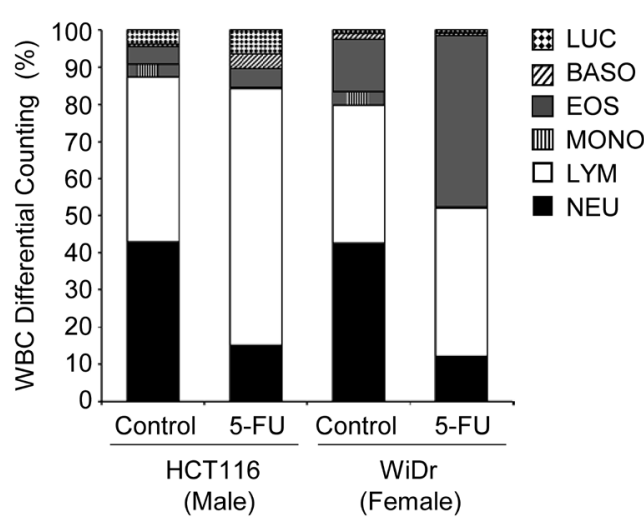

Fig. 2. Female Mouse Xenograft Model Showed Inhibition of Tumor Growth and Higher Hematological Toxicity Due to 5-FU Treatment Compared with Male Mouse Xenograft Model

(A)-(B), HCT116 and WiDr cells were subcutaneously injected into female and male mice, respectively. Tumor-bearing mice were randomized into two groups: control mice and treated mice injected intraperitoneally with $50 \mathrm{mg} / \mathrm{kg} 5$-FU three times a week for three weeks. Tumor volume (mm ${ }^{3}$ ) was measured three times each week for $21 \mathrm{~d}$ in HCT116-xenograft model (A) and in WiDr-xenograft model (B). (C)-(D), The average number of WBC (C) and WBC differential counts (D) were determined via hematological analysis in blood samples. Data are expressed as mean \pm S.D. ****Statistically significant at $p<0.05$ and $p<0.001$, respectively. 
Table 2. Changes of Hematological Parameters by 5-FU Treatment in Male and Female Mouse Xenograft Models

\begin{tabular}{|c|c|c|c|c|c|c|c|}
\hline \multirow{2}{*}{\multicolumn{2}{|c|}{ Factors }} & \multicolumn{3}{|c|}{ HCT116 (Male) } & \multicolumn{3}{|c|}{ WiDr (Female) } \\
\hline & & Control & $5-\mathrm{FU}$ & $p$-Value & Control & $5-\mathrm{FU}$ & $p$-Value \\
\hline \multicolumn{2}{|c|}{$\mathrm{RBC}\left(\times 10^{6}\right.$ cells $\left./ \mu \mathrm{L}\right)$} & $8.73 \pm 0.84$ & $6.80 \pm 0.55$ & $0.011^{*}$ & $9.05 \pm 0.42$ & $8.02 \pm 0.74$ & 0.063 \\
\hline \multicolumn{2}{|c|}{ HGB (g/dL) } & $14.08 \pm 1.28$ & $11.40 \pm 0.58$ & $0.018^{*}$ & $14.63 \pm 0.54$ & $13.00 \pm 1.25$ & 0.074 \\
\hline \multicolumn{2}{|c|}{ HCT (\%) } & $44.53 \pm 4.48$ & $34.65 \pm 2.46$ & $0.014^{*}$ & $46.03 \pm 1.97$ & $41.23 \pm 3.89$ & 0.086 \\
\hline \multicolumn{2}{|c|}{ MCV (fL) } & 50.9. \pm 0.43 & $50.98 \pm 1.95$ & 0.963 & $50.83 \pm 0.43$ & $51.40 \pm 1.73$ & 0.560 \\
\hline \multicolumn{2}{|c|}{$\mathrm{MCH}(\mathrm{pg})$} & $16.15 \pm 0.19$ & $16.80 \pm 0.93$ & 0.258 & $16.15 \pm 0.48$ & $16.18 \pm 0.31$ & 0.934 \\
\hline \multicolumn{2}{|c|}{$\mathrm{MCHC}(\mathrm{g} / \mathrm{dL})$} & $31.68 \pm 0.49$ & $32.98 \pm 2.26$ & 0.336 & $31.80 \pm 0.81$ & $31.50 \pm 0.45$ & 0.549 \\
\hline \multicolumn{2}{|c|}{ RDW (\%) } & $13.90 \pm 1.75$ & $17.68 \pm 2.53$ & 0.055 & $13.13 \pm 0.69$ & $17.35 \pm 1.27$ & $0.003 *$ \\
\hline \multicolumn{2}{|c|}{$\mathrm{WBC}\left(\times 10^{3}\right.$ cells $\left./ \mu \mathrm{L}\right)$} & $2.17 \pm 1.05$ & $0.82 \pm 0.37$ & 0.076 & $2.31 \pm 0.36$ & $0.36 \pm 0.09$ & $0.001 *$ \\
\hline \multirow[t]{2}{*}{ NEU } & $\times 10^{3}$ cells $/ \mu \mathrm{L}$ & $1.03 \pm 0.65$ & $0.10 \pm 0.04$ & 0.064 & $0.93 \pm 0.17$ & $0.04 \pm 0.02$ & $0.002 *$ \\
\hline & $\%$ & $42.80 \pm 19.94$ & $15.70 \pm 9.06$ & 0.066 & $42.90 \pm 11.23$ & $11.95 \pm 6.24$ & $0.006^{*}$ \\
\hline \multirow[t]{2}{*}{ LYM } & $\times 10^{3}$ cells $/ \mu \mathrm{L}$ & $0.91 \pm 0.44$ & $0.51 \pm 0.19$ & 0.163 & $0.88 \pm 0.34$ & $0.14 \pm 0.13$ & $0.017 *$ \\
\hline & $\%$ & $44.50 \pm 14.30$ & $71.93 \pm 8.06$ & $0.022 *$ & $37.60 \pm 3.14$ & $40.32 \pm 33.52$ & 0.882 \\
\hline \multirow[t]{2}{*}{ MONO } & $\times 10^{3}$ cells $/ \mu \mathrm{L}$ & $0.09 \pm 0.06$ & $0.00 \pm 0.00$ & 0.063 & $0.08 \pm 0.05$ & $0.00 \pm 0.00$ & 0.054 \\
\hline & $\%$ & $3.60 \pm 2.39$ & $0.38 \pm 0.26$ & 0.073 & $3.55 \pm 1.18$ & $0.20 \pm 0.22$ & $0.010^{*}$ \\
\hline \multirow[t]{2}{*}{ EOS } & $\times 10^{3}$ cells $/ \mu \mathrm{L}$ & $0.08 \pm 0.01$ & $0.03 \pm 0.03$ & $0.040^{*}$ & $0.36 \pm 0.30$ & $0.18 \pm 0.15$ & 0.322 \\
\hline & $\%$ & $4.65 \pm 2.34$ & $5.43 \pm 6.45$ & 0.833 & $14.45 \pm 10.57$ & $46.55 \pm 39.47$ & 0.203 \\
\hline \multirow[t]{2}{*}{ BASO } & $\times 10^{3}$ cells $/ \mu \mathrm{L}$ & $0.02 \pm 0.02$ & $0.03 \pm 0.02$ & 0.321 & $0.03 \pm 0.01$ & $0.00 \pm 0.00$ & $0.004 *$ \\
\hline & $\%$ & $0.73 \pm 0.58$ & $4.18 \pm 2.46$ & 0.064 & $1.45 \pm 0.51$ & $0.58 \pm 0.76$ & 0.112 \\
\hline \multirow[t]{2}{*}{ LUC } & $\times 10^{3}$ cells $/ \mu \mathrm{L}$ & $0.04 \pm 0.06$ & $0.05 \pm 0.05$ & 0.876 & $0.02 \pm 0.01$ & $0.00 \pm 0.01$ & $0.002 *$ \\
\hline & $\%$ & $3.70 \pm 6.34$ & $6.63 \pm 6.63$ & 0.547 & $0.95 \pm 0.24$ & $0.83 \pm 1.06$ & 0.832 \\
\hline \multicolumn{2}{|c|}{$\operatorname{PLT}\left(\times 10^{3}\right.$ cells $\left./ \mu \mathrm{L}\right)$} & $1077.50 \pm 146.61$ & $1442.75 \pm 641.44$ & 0.341 & $946.50 \pm 308.70$ & $1326.25 \pm 157.54$ & 0.087 \\
\hline \multicolumn{2}{|c|}{ MPV (fL) } & $7.23 \pm 1.76$ & $8.15 \pm 0.96$ & 0.402 & $8.45 \pm 0.66$ & $7.53 \pm 1.19$ & 0.235 \\
\hline
\end{tabular}

Abbreviation: RBC, Red blood cell; HGB, Hemoglobin; HCT, Hematocrit; MCV, Mean corpuscular volume; MCH, Mean corpuscular hemoglobin; MCHC, Mean corpuscular hemoglobin concentration; RDW, Red blood cell distribution width; WBC, White blood cell; NEU, Neutrophil; LYM, Lymphocyte; MONO, Monocyte; EOS, Eosinophil; BASO, Basophil; LUC, Large unstained cell; PLT, platelet; MPV, Mean platelet volume. These data represent average \pm standard deviation $(n=5 /$ group $)$. ${ }^{*}$ Significant at $p<0.05$ when compared with control.

inhibited cell viability of female-derived cell lines more effectively than in male-derived cell lines.

5-FU Exerts Stronger Inhibition of Tumor Growth and Hematological Toxicity in a Female than in a Male Mouse Xenograft Model We next investigated the in vivo relevance of the sex differences in 5-FU-induced cytotoxicity of colon cancer cell lines. To this end, we established two xenograft mouse models: one with a male-derived human colon cancer cell line HCT116 injected into male mice (a male xenograft model) and another involving a female-derived human colon cancer cell line WiDr injected into female mice (a female xenograft model). Treatment with 5-FU in male xenograft model inhibited the tumor volume, but not statistically significantly (Fig. 2A). By contrast, tumor volume was significantly reduced by $61 \%$ in female xenograft model treated with 5 -FU (Fig. 2B).

Hematological parameters were determined in blood samples obtained from male or female xenograft model injected with 5-FU (Table 2, Figs. 2C, D). The average number of white blood cells (WBC) was significantly reduced by $85 \%$ in female xenograft mice treated with 5-FU at $p<0.001$ (Fig. $2 \mathrm{C}$ ), while it was not significantly reduced in male xenograft model. As shown in Table 2 and Fig. 2D, the absolute NEU count in female mouse model was significantly decreased by 5 -FU treatment $(p=0.002)$. The percentage $(\%)$ of NEU in total WBC was also significantly decreased by 5 -FU in female xenograft model $(p=0.006)$. In contrast, no significant decrease was observed in the absolute number or the percentage of NEU in male-xenograft model following same treatment. Given the possibility of neutropenia in decreased number of NEU, ${ }^{23,24)}$ the results suggest that 5-FU may induce more severe neutropenia in female xenograft model than in male xenograft model. These data using two sex-specific xenograft models provide in vivo evidence supporting sex differences in 5-FU treatment in tumor growth and hematological toxicity.

Clinical Characteristics of Korean Colorectal Cancer Patients Treated with 5-FU To determine the clinical relevance of our findings in Korean population, we retrospectively analyzed the data from the Korean colorectal cancer patients enrolled at the SNUH. A total of 357 adult colorectal cancer patients ( $\geq 19$ years) enrolled at the SNUH (from 1 January 2012 to 31 December 2016) received FL regimen: $212(59.4 \%)$ men and 145 (40.6\%) women. The FL regimen included 5-FU bolus chemotherapy administered on 5 consecutive days every 4 weeks for 6 cycles. Baseline clinical characteristics of men and women patients are summarized in Table 3. The median age of total patients was 62 years. A total of 306 patients (86.6\% of total patients) were at stage II without metastasis. The percentage of stage II colorectal cancer patients among women was $90.3 \%$, higher than that of men $(84.0 \%)$ with a $p$-value of 0.056 .

Female Colorectal Cancer Patients Treated with 5-FU Experience Leukopenia and Alopecia More Frequently than Male Patients To investigate if the 5-FU-induced adverse drug reactions were sex-dependent, we analyzed major adverse drug reactions including neutropenia, alopecia, nausea/vomiting, diarrhea, and hand-foot syndrome in 357 Korean colorectal cancer patients from SNUH received 5-FU (Table 4). The usual dose of 5-FU in SNUH in FL regimen was $425 \mathrm{mg} / \mathrm{m}^{2}$. There was no significant sex difference in the 
Table 3. Characteristics of 357 Korean Colorectal Cancer Patients Treated with 5-FU

\begin{tabular}{|c|c|c|c|c|}
\hline Characteristics & Total $(n=357)$ & $\operatorname{Men}(n=212)$ & Women $(n=145)$ & $p$-Value \\
\hline Age, yrs (mean \pm S.D.) & $61.7 \pm 10.7$ & $63.6 \pm 8.9$ & $59.5 \pm 12.2$ & 0.148 \\
\hline Site, $n(\%)$ & & & & 0.458 \\
\hline Cecum & $20(5.6)$ & $8(3.8)$ & $12(8.3)$ & 0.058 \\
\hline Ascending & $68(19.0)$ & $35(16.5)$ & $33(22.8)$ & 0.091 \\
\hline Transverse & $19(5.3)$ & $10(4.7)$ & $9(6.2)$ & 0.350 \\
\hline Descending & $12(3.4)$ & $7(3.3)$ & $5(3.5)$ & 0.581 \\
\hline Sigmoid & $123(34.5)$ & $79(37.3)$ & $44(30.3)$ & 0.108 \\
\hline Rectum & $77(21.6)$ & $50(23.6)$ & $27(18.6)$ & 0.161 \\
\hline Others & $38(10.6)$ & $23(10.8)$ & $15(10.3)$ & 0.513 \\
\hline Stage, $n(\%)$ & & & & 0.221 \\
\hline I & $7(1.9)$ & $5(2.4)$ & $2(1.4)$ & 0.405 \\
\hline II & $309(86.6)$ & $178(84.0)$ & $131(90.3)$ & 0.056 \\
\hline III & $41(11.5)$ & $29(13.6)$ & $12(8.3)$ & 0.079 \\
\hline
\end{tabular}

Abbreviation: yrs, years; S.D., standard deviation. Enrolled patients in the SNUH ( $\geq 19$ years) Korea, 2012-2016.

Table 4. Adverse Drug Reactions to 5-FU in 357 Korean Colorectal Cancer Patients

\begin{tabular}{|c|c|c|c|c|}
\hline Factors & Total & Men & Women & $p$-Value \\
\hline No. of patients, $n(\%)$ & $357(100)$ & $212(59.4)$ & $145(40.6)$ & \\
\hline \multicolumn{5}{|l|}{ 5-FU dose } \\
\hline Initial dose, $\mathrm{mg} / \mathrm{m}^{2}$ (mean \pm S.D.) & $378.3 \pm 38.5$ & $380.1 \pm 36.9$ & $375.6 \pm 40.7$ & 0.660 \\
\hline Final dose, $\mathrm{mg} / \mathrm{m}^{2}$ (mean \pm S.D.) & $370.1 \pm 42.3$ & $371.8 \pm 41.8$ & $367.6 \pm 43.0$ & 0.314 \\
\hline Patients with adverse drug reactions, $n(\%)$ & $284(79.6)$ & $167(78.9)$ & $117(80.7)$ & 0.381 \\
\hline Neutropenia & $206(57.7)$ & $127(59.9)$ & $79(54.5)$ & 0.308 \\
\hline Alopecia & $27(7.6)$ & $6(2.8)$ & $21(14.5)$ & $<0.001 *$ \\
\hline Nausea/Vomiting & $101(28.3)$ & $55(25.9)$ & $46(31.7)$ & 0.234 \\
\hline Diarrhea & $100(28.0)$ & $62(29.2)$ & $38(26.2)$ & 0.530 \\
\hline Hand-foot syndrome & $14(3.9)$ & $9(4.2)$ & $5(3.4)$ & 0.703 \\
\hline No. of adverse events in each patients & 1.25 & 1.22 & 1.30 & 0.706 \\
\hline
\end{tabular}

Abbreviation: S.D., standard deviation. Enrolled patients in the SNUH ( $\geq 19$ years) Korea, 2012-2016; *Significant at $p<0.05$ when compared with men.

initial and final doses of 5-FU treatment between male and female. Adverse drug reactions were detected in $78.9 \%$ of males and $80.7 \%$ of females. No statistical differences in neutropenia, nausea/vomiting, diarrhea, and hand foot syndrome were found between male and female. Notably, the sex difference in alopecia was significant at $p<0.001$. About $14.5 \%$ of female experienced alopecia, while $2.8 \%$ of male experienced same adverse drug reaction. Also, we analyzed the effectiveness of 5-FU on 5-year survival in male and female patients. As shown in Fig. 3, there was no statistically significant sex difference between men and women treated with 5-FU in 5-year survival.

Furthermore, we interrogated the data from adverse drug event reporting system of KIDS from 1 January 2011 to 31 December 2015. Spontaneously reported adverse drug reactions to 5-FU in 1094 colorectal cancer patients ( $\geq 19$ years), 640 males $(58.5 \%)$ and 454 females $(41.5 \%)$, were analyzed for adverse drug reactions to 5-FU (Table 5). A total of 1446 cases with 847 males and 599 females were identified excluding cases of combined medication, duplication, and causality assessment, which were considered 'unlikely,' 'unclassified,' and 'unclassifiable.' There was no significant sex difference in the doses of 5-FU between male and female. A total of $15.2 \%$ of females experienced leukopenia, significantly higher than males $(8.3 \%)$ at $p=0.001$. There was no significant sex difference in nausea, vomiting, diarrhea, and stomatitis. Overall,

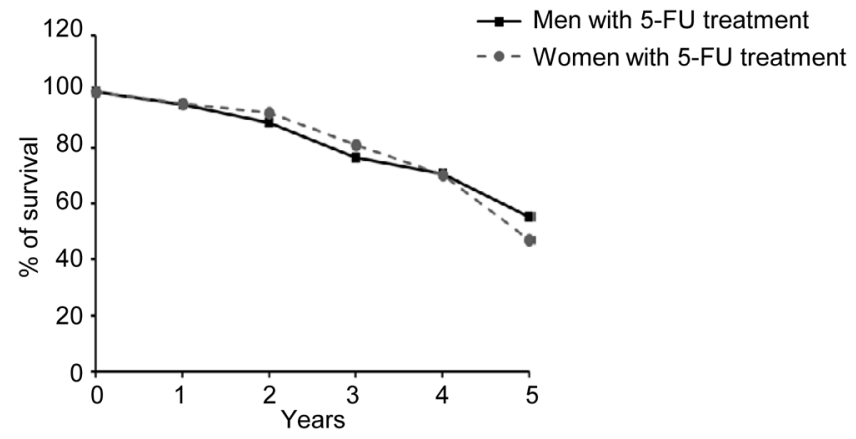

Fig. 3. The 5-Year Survival Rate of Male and Female Colorectal Cancer Patients Treated with 5-FU in SNUH

data from SNUH showed that female colorectal cancer patients experienced alopecia more frequently than male patients following 5-FU treatment, while the data from KIDS revealed that leukopenia and alopecia were more frequently reported in females than in males.

\section{DISCUSSION}

Men and women exhibit several differences in genetic and metabolic factors that are associated with the risk of diseases and drug responsiveness. For the first time, we investigated 
Table 5. Adverse Drug Reactions to 5-FU in 1094 Korean Colorectal Cancer Patients

\begin{tabular}{|c|c|c|c|c|}
\hline Factors & Total $(n=1094) n(\%)$ & Men $(n=640) n(\%)$ & Women $(n=454) n(\%)$ & $p$-Value \\
\hline 5-FU dose $\mathrm{mg}($ mean \pm S.D. $)$ & $1697 \pm 70.11$ & $1790 \pm 115.4$ & $1566 \pm 46.23$ & 0.116 \\
\hline $\mathrm{mg} / \mathrm{m}^{2}($ mean \pm S.D. $)$ & $1025 \pm 239.4$ & $1127 \pm 304.2$ & $800 \pm 400$ & 0.545 \\
\hline No. of total adverse drug reactions & $1446(100)$ & $847(59.2)$ & $599(40.8)$ & 1.000 \\
\hline Leukopenia & $161(11.1)$ & $70(8.3)$ & $91(15.2)$ & $0.001 *$ \\
\hline Nausea & $281(19.4)$ & $162(19.1)$ & $119(19.9)$ & 0.753 \\
\hline Vomiting & $96(6.6)$ & $61(7.2)$ & $35(5.8)$ & 0.323 \\
\hline Diarrhea & $43(3.0)$ & $28(3.3)$ & $15(2.5)$ & 0.384 \\
\hline Stomatitis & $13(0.9)$ & $9(1.1)$ & $4(0.7)$ & 0.435 \\
\hline Others & $852(58.9)$ & $517(61.0)$ & $335(55.9)$ & 0.146 \\
\hline No. of adverse events in each patients & 1.29 & 1.27 & 1.30 & 0.641 \\
\hline
\end{tabular}

Abbreviation: S.D., standard deviation. Reported data in the KIDS ( $\geq 19$ years) Korea, 2011-2015; *Significant at $p<0.05$ when compared with men.

the sex-specific differences in response to 5-FU treatment using human colon cancer cell lines and female and male xenograft tumor mouse models. We showed that 5-FU-induced cytotoxicity was greater in female-derived colon cancer cell lines than in male-derived colon cancer cell lines (Fig. 1, Table 1). In addition, we showed that inhibition of tumor growth was greater following 5-FU treatment in a female xenograft model than in a male xenograft model (Figs. 2A, 2B). It was reported that a low level of dihydropyrimidine dehydrogenase (DPD), the initial enzyme catabolizing pyrimidine, was associated with severe toxicity of $5-\mathrm{FU}^{25)}$ Women patients diagnosed with colorectal cancer might be more sensitive to 5-FU, because of a lower level of DPD in women. ${ }^{26}$ Drug metabolism and elimination are sex-dependent and influenced by sex hormones, menopause, and menstruation. ${ }^{27)}$ Sex-selective toxicity may be influenced by sex-dependent disparities in pharmacokinetic and pharmacodynamics of several drugs. ${ }^{28)}$ The different toxicity between male and female may be associated with different pharmacokinetics to sex. ${ }^{27)}$ The detailed molecular mechanism of 5-FU-induced side effects based on sex-specific differences between men and women remains to be further elucidated.

The reason why we used a xenograft animal model in our study was because there was a report examined the sex difference by 5 -FU using male and female animals without xenograft. ${ }^{29)}$ In this paper, there were no significant sex differences of the survival rates and body weights in both male and female mice treated with $60 \mathrm{ppm} 5$-FU. ${ }^{29)}$ Disparity in chemical-induced toxicity has been detected between female and male animals. Cisplatin-induced nephrotoxicity was greater in male rats than in female rats. ${ }^{30)}$ Our results showed that 5-FU treatment induced lower $\mathrm{WBC}$ and NEU levels in a female xenograft model than in a male xenograft model (Figs. 2C, D, Table 2). These findings suggest that sex may be considered as a crucial factor underlying toxicity.

Differences in types of 5-FU toxicities may be attributed to genetic and dietary disparities among Asian, European, and Americans populations. ${ }^{31)}$ In breast and lung cancers, Asian populations showed greater toxicity induced by anticancer agents such as doxorubicin and irinotecan, than Caucasian populations. ${ }^{32)}$ In Caucasian and African American populations, 5-FU toxicities including leukopenia and alopecia were frequently and severely experienced in females than in males. ${ }^{20,21)}$ Consistently, we demonstrated that the incidence of alopecia and leukopenia was higher in females than in males among Korean colorectal cancer patients who received 5-FU (Tables 4, 5). Although we analyzed the data of a small sample of patients due to the limitations of retrospective analysis, this is the first report showing sex-based differences in response to 5-FU-based chemotherapy in Korean populations. Further prospective studies are needed to determine sex-specific differences in clinical trials of colorectal cancer treatment using 5-FU as a therapeutic agent.

Taken together, our results showed that 5-FU-induced toxicity was greater in females than in males, providing substantial evidence supporting appropriate 5-FU based-chemotherapy based on sex as a crucial factor. It is worthwhile to further elucidate the role of 5-FU based-chemotherapy according to sex in colorectal cancer. Adequate sex-specific treatment of patients is required to ensure appropriate QOL and extend survival. Our findings provided valuable information regarding the safe use of 5-FU in patients suffering from colorectal cancer, suggesting a desirable 5-FU-based regimen for colorectal cancer. Additional data are needed to reinforce the evidence supporting sex differences to enhance the effectiveness of chemotherapy and minimize adverse drug reactions to anticancer drugs.

Acknowledgments The present study was supported by the National Research Foundation (NRF) funded by the Korean government (No. 2015M3A9B6074045 and No. 2016H1C3A1903202).

Conflict of Interest The authors declare no conflict of interest.

\section{REFERENCES}

1) Boehmer U, Cooley TP, Clark MA. Cancer and men who have sex with men: a systematic review. Lancet Oncol., 13, e545-e553 (2012).

2) Clocchiatti A, Cora E, Zhang Y, Dotto GP. Sexual dimorphism in cancer. Nat. Rev. Cancer, 16, 330-339 (2016).

3) Becker JB, Arnold AP, Berkley KJ, Blaustein JD, Eckel LA, Hampson E, Herman JP, Marts S, Sadee W, Steiner M, Taylor J, Young E. Strategies and methods for research on sex differences in brain and behavior. Endocrinology, 146, 1650-1673 (2005).

4) Keitt SK, Fagan TF, Marts SA. Understanding sex differences in environmental health: a thought leaders' roundtable. Environ. Health Perspect., 112, 604-609 (2004).

5) Zucker I, Beery AK. Males still dominate animal studies. Nature, 
465, 690 (2010).

6) Islam MM, Iqbal U, Walther BA, Nguyen PA, Li YJ, Dubey NK, Poly TN, Masud JHB, Atique S, Syed-Abdul S. Gender-based personalized pharmacotherapy: a systematic review. Arch. Gynecol. Obstet., 295, 1305-1317 (2017).

7) Huang RS, Kistner EO, Bleibel WK, Shukla SJ, Dolan ME. Effect of population and gender on chemotherapeutic agent-induced cytotoxicity. Mol. Cancer Ther., 6, 31-36 (2007).

8) Shah K, McCormack CE, Bradbury NA. Do you know the sex of your cells? Am. J. Physiol. Cell Physiol., 306, C3-C18 (2014).

9) Wizemann TM, Pardue ML. Exploring the Biological Contributions to Human Health: Does Sex Matter? National Academies Press, Washington (DC) (U.S.) (2001).

10) Miller VM. In pursuit of scientific excellence: sex matters. $A d v$. Physiol. Educ., 36, 83-84 (2012).

11) Kim SE, Paik HY, Yoon H, Lee JE, Kim N, Sung MK. Sex- and gender-specific disparities in colorectal cancer risk. World J. Gastroenterol., 21, 5167-5175 (2015).

12) Chacko L, Macaron C, Burke CA. Colorectal cancer screening and prevention in women. Dig. Dis. Sci., 60, 698-710 (2015).

13) $\mathrm{Ng} \mathrm{SC,} \mathrm{Wong} \mathrm{SH.} \mathrm{Colorectal} \mathrm{cancer} \mathrm{screening} \mathrm{in} \mathrm{Asia.} \mathrm{Br.} \mathrm{Med.}$ Bull., 105, 29-42 (2013).

14) Siegel RL, Miller KD, Jemal A. Cancer statistics, 2015. CA Cancer J. Clin., 65, 5-29 (2015).

15) Lim D, Ha M, Song I. Trends in major cancer mortality in Korea, 1983-2012, with a joinpoint analysis. Cancer Epidemiol., 39, 939946 (2015).

16) Nelson RL, Dollear T, Freels S, Persky V. The relation of age, race, and gender to the subsite location of colorectal carcinoma. Cancer, 80, 193-197 (1997).

17) Wichmann MW, Müller C, Hornung HM, Lau-Werner U, Schildberg FW; Colorectal Cancer Study Group. Gender differences in long-term survival of patients with colorectal cancer. Br. J. Surg., 88, 1092-1098 (2001).

18) Che J, Pan L, Yang X, Liu Z, Huang L, Wen C, Lin A, Liu H. Thymidine phosphorylase expression and prognosis in colorectal cancer treated with 5-fluorouracil-based chemotherapy: A meta-analysis. Mol. Clin. Oncol., 7, 943-952 (2017).

19) O'Connell MJ, Mailliard JA, Kahn MJ, Macdonald JS, Haller DG, Mayer RJ, Wieand HS. Controlled trial of fluorouracil and low-dose leucovorin given for 6 months as postoperative adjuvant therapy for colon cancer. J. Clin. Oncol., 15, 246-250 (1997).
20) Sloan JA, Goldberg RM, Sargent DJ, Vargas-Chanes D, Nair S, Cha SS, Novotny PJ, Poon MA, O'Connell MJ, Loprinzi CL. Women experience greater toxicity with fluorouracil-based chemotherapy for colorectal cancer. J. Clin. Oncol., 20, 1491-1498 (2002).

21) Chansky K, Benedetti J, Macdonald JS. Differences in toxicity between men and women treated with 5-fluorouracil therapy for colorectal carcinoma. Cancer, 103, 1165-1171 (2005).

22) Lee KH, Koh M, Moon A. Farnesyl transferase inhibitor FTI-277 inhibits breast cell invasion and migration by blocking H-Ras activation. Oncol. Lett., 12, 2222-2226 (2016).

23) Boxer L, Dale DC. Neutropenia: causes and consequences. Semin. Hematol., 39, 75-81 (2002).

24) Everds NE. Hematology of the Laboratory Mouse. The Mouse in Biomedical Research, History, Wild Mice, and Genetics. (Fox JG, Barthold S, Davisson M, Newcomer CE, Quimby FW, Smith A eds) Vol. 2, Elselver, Academic Press, New York, pp. 133-170 (2006).

25) Harris BE, Carpenter JT, Diasio RB. Severe 5-fluorouracil toxicity secondary to dihydropyrimidine dehydrogenase deficiency. A potentially more common pharmacogenetic syndrome. Cancer, $\mathbf{6 8}$, 499-501 (1991).

26) Yamashita K, Mikami Y, Ikeda M, Yamamura M, Kubozoe T, Urakami A, Yoshida K, Kimoto M, Tsunoda T. Gender differences in the dihydropyrimidine dehydrogenase expression of colorectal cancers. Cancer Lett., 188, 231-236 (2002).

27) Gabriele L, Buoncervello M, Ascione B, Bellenghi M, Matarrese $\mathrm{P}$, Carè $\mathrm{A}$. The gender perspective in cancer research and therapy: novel insights and on-going hypotheses. Ann. Ist. Super. Sanita, 52, 213-222 (2016).

28) Wang J, Huang Y. Pharmacogenomics of sex difference in chemotherapeutic toxicity. Curr. Drug Discov. Technol., 4, 59-68 (2007).

29) Iwagawa M, Nakamura M, Izumi K, Otsuka H. Carcinogenicity testing of 5 -fluorouraciil in $(\mathrm{C} 57 \mathrm{BL} / 6 \times \mathrm{C} 3 \mathrm{H}) \mathrm{F}_{1}$ mice. J. Toxicol. Pathol., 4, 129-135 (1991).

30) Nematbakhsh M, Ebrahimian S, Tooyserkani M, Eshraghi-Jazi F, Talebi A, Ashrafi F. Gender difference in Cisplatin-induced nephrotoxicity in a rat model: greater intensity of damage in male than female. Nephrourol. Mon., 5, 818-821 (2013).

31) Shastry BS. Genetic diversity and new therapeutic concepts. $J$. Hum. Genet., 50, 321-328 (2005).

32) Phan VH, Moore MM, McLachlan AJ, Piquette-Miller M, Xu H, Clarke SJ. Ethnic differences in drug metabolism and toxicity from chemotherapy. Expert Opin. Drug Metab. Toxicol., 5, 243-257 (2009). 